\title{
8. Measuring Citizen Feedback and Gauging Citizen Satisfaction
}

\author{
Bette-Jo Hughes
}

On behalf of my colleagues in Canada, I am honoured to use my contribution to this volume as an opportunity to explore the work that we are doing in the field of citizen-centred service delivery. Australia and New Zealand are similar to Canada in many ways, and I think each country can learn from the other.

In reading Staying Ahead of the Game, the Australian Government's 2010 reform white paper for its federal public service, it strikes me that we could replace the country names and the document would be just as valid in Canada, as we are focused on similar challenges. Equally, I understand that the work undertaken by New Zealand's Experience Research Programme (or NZE) undertaken in the State Services Commission is having great success in providing evidence to inform improvements to service delivery in that country. The focus of both works is relevant in Canada.

As the Assistant Deputy Minister for Service in British Columbia (Service BC), I am a service delivery practitioner; I am responsible for operations that provide services directly to citizens, in person, by telephone and online. To give some perspective, British Colombia is the westernmost province in Canada, with a similarly sized population to Queensland and similar in geographic size to New South Wales. In my contribution to this collection of essays, I will be exploring the key factors that contribute to successful citizen-centred service delivery work in Canada in general and in British Colombia specifically.

In Canada, citizen-centred service is not a new concept. Consider that in 1996 the Canadian federal deputy minister's task force on service delivery models stated that:

Citizen-centric service incorporates citizens' concerns at every stage of the service design and delivery process; that is, citizens' needs become the organising principle around which the public interest is determined and service delivery is planned.

Though this quote illustrates the fact that the concept of citizen-centric service delivery has been with us for a significant amount of time, the drivers that motivated this change in focus in 1996 are very similar to the conversations we are having today. 
We are all reviewing our programs, we all have resource challenges, and we work with the expectations that if citizens are changing, then the public service needs to transform to address these issues. We have made a good start in the process. Specifically, we are focusing on the citizens' view of government services - looking from the outside in - and we are taking citizens' concerns and needs into account at every stage of design and delivery. The next phase, which is a key theme in this volume of essays, is how we truly engage people in the conversation - not just asking how they are doing, but involving them, from the beginning, in the design of policies and services.

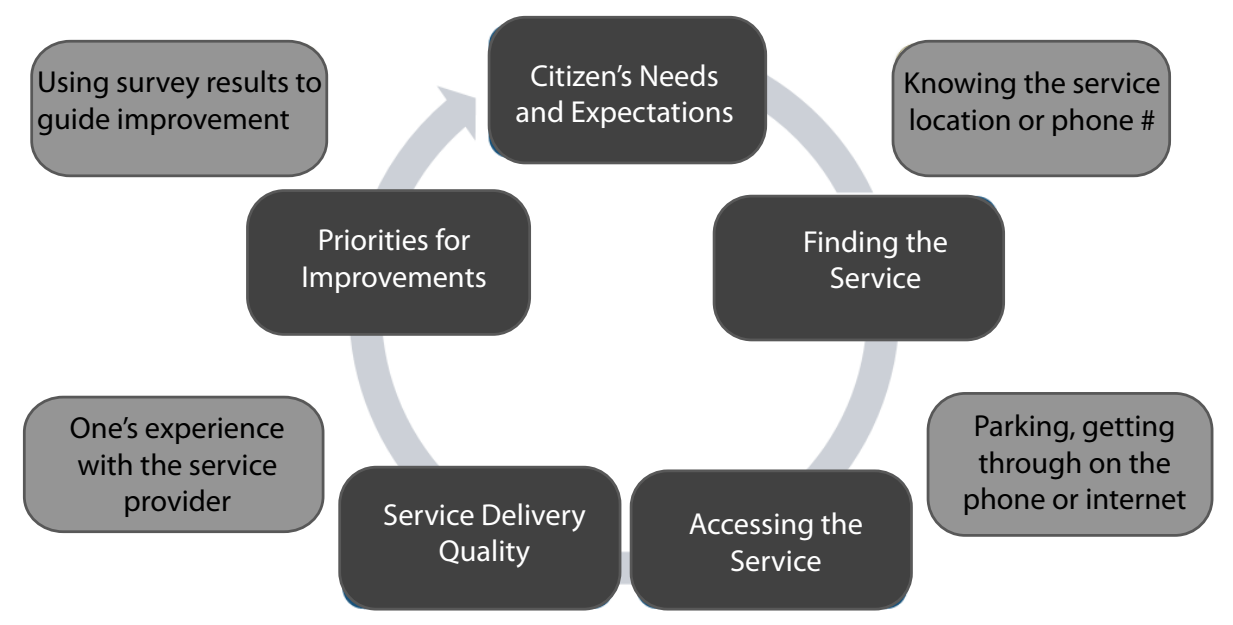

Figure 1: How government service looks from the outside-in

Source: Author's research.

A significant body of research on this topic has become institutionalised in Canada. Service BC's own citizen consultation on this topic used a variety of modes of research including quantitative surveys, exit interviews, focus groups, and blogs with citizens and front-line service workers.

Our research shows that Canadian citizens expect as good or better service from the public sector than they do from the private sector. Citizens often need more than one government service - especially when dealing with life events such as birth, death, travel, unemployment and internal migration within Canada. Moreover, the research uncovered some disturbing findings about how Canadian citizens interact with and access their public services. Namely:

- 26 per cent of those interviewed did not know where to start to find the service that they needed (principal reason given: confusing web pages or services not well advertised).

- 23 per cent of those interviewed said it was difficult to access the people or information they needed (principal reason given: busy telephones, broken links, being told their query was 'not my department' by service staff). 
- Citizens said they were often required to manage the 'white space' that exists between related services (e.g., service bundles/clusters).

Overall, public services in Canada received an average service quality score of 72 out of 100 from those interviewed.

The next challenge for the research is to think about the measurement of the entire service experience versus the transaction, especially as the delivery of services now occurs through public and private organisations such as community service organisations.

The research has also supported the growth and persistence of single-window service delivery, which is successful when we:

- focus on delivering the right service

- use the appropriate service channel depending on the type of service

- use the right resources depending on the complexity of the transaction.

What makes this work is a shared vision, and broad acceptance and support that there are many ways to get there.

We believe there are five factors that drive service satisfaction: timeliness, knowledge and competence, courtesy/going the extra mile, fairness, and outcome. When all five are performed well, we found public services score 87 out of 100; when one driver fails the score drops to 74 out of 100; when four fail, it becomes 37 out of 100. Timeliness is the most important driver across all services and the telephone channel remains the priority for improvement. Figure 2 shows the long-term trend for customer satisfaction in Canada for 26 services.

Figure 3 shows the structure of the system used in Canada. Service improvements for citizens occur when the process is operationalised in a repetitive cycle.

The Institute for Citizen-Centric Service (ICCS) is a collaborative venture that engages all three orders of government across Canada and which promotes and supports improved service delivery by listening to and acting on the voice of the citizen. Specifically, it:

- supports two national service delivery councils

- manages an inter-governmental research agenda

- gathers, preserves and disseminates knowledge and innovative practices

- provides universally applicable tools and learning content through the establishment of a common standard for measuring the efficacy of service delivery, as well as providing service certification and learning

- builds capacity. 


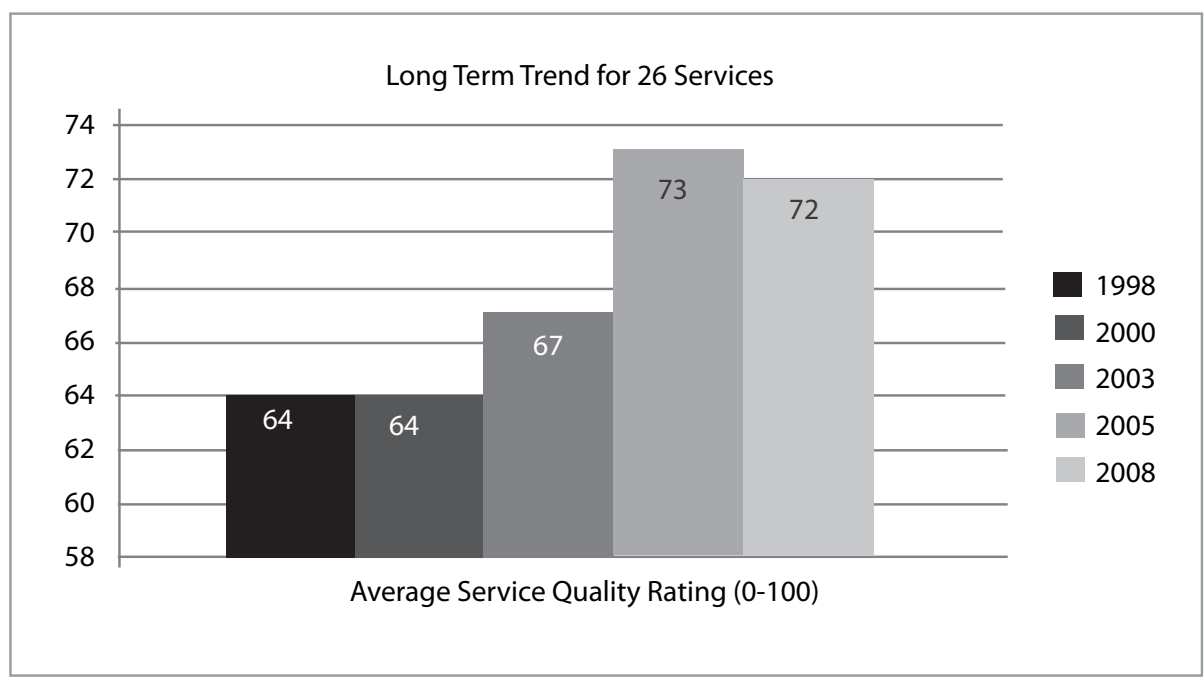

Figure 2: Federal, provincial, municipal service satisfaction performance trends

Source: Service BC, Government of British Columbia 2011.

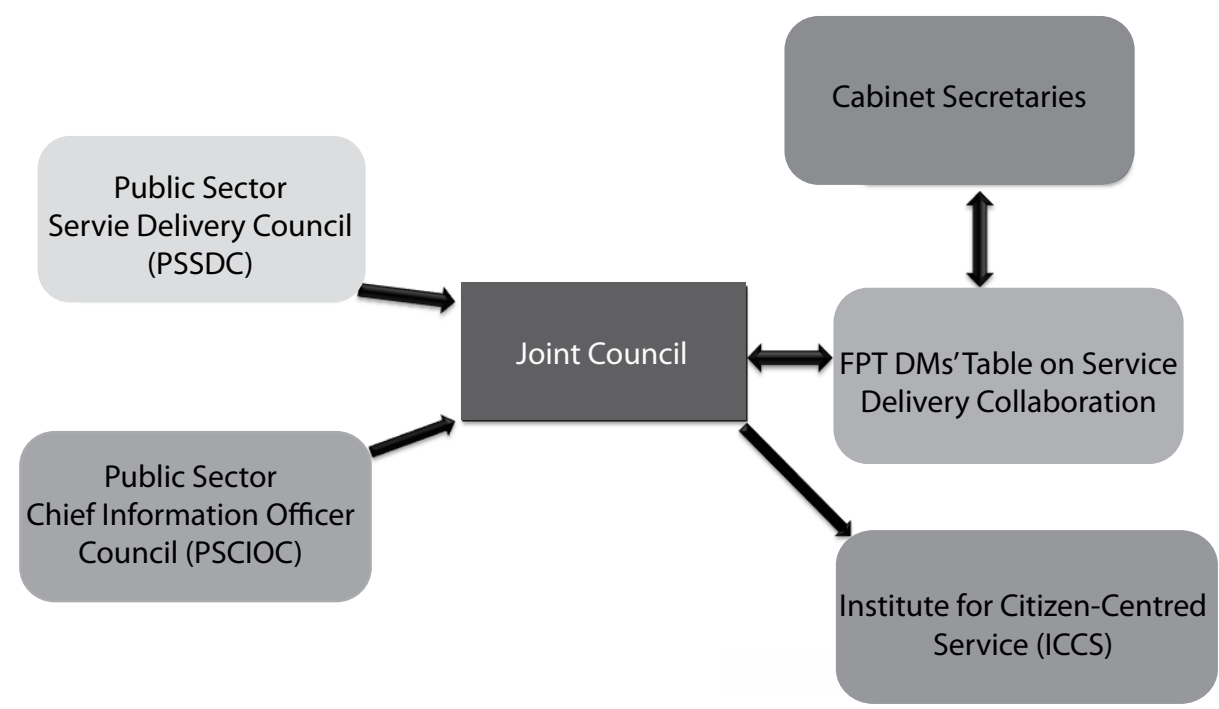

Figure 3: Service delivery community in Canada

Source: Author's research. 
Specifically in British Columbia, our strategic decision-making is guided by our Gov 2.0 strategy, which was released in late 2010. Gov 2.0 outlines the focus on:

- empowering citizens to create value from government data

- saving citizens time in their interactions with government

- encouraging collaboration to deliver better quality services to citizens

- saving citizens time in their interactions with government

- encouraging collaboration to deliver better quality services to citizens.

British Columbia recently released our open government platform, OpenData. Learning from Australia's and New Zealand's open data websites, we hope OpenData will empower users to make better decisions that help people save time and money, help solve problems that matter in communities and encourage citizens and the private sector to innovate. After all, if we want citizens to engage with us in a dialogue about improving government policy and service delivery, we need to provide them with access to the same information that we have.

OpenData is the first provincial open data site in Canada and offers the largest number of data sets available on any government site in the country - nearly 2500 sets of data and growing, ranging from demographic information to education outcomes, fish habitat, and birth and death rates. The data is free, searchable and available for anyone to use. There is direction from our premier to ministries to continue to add more data and to think about the release of the data when they are building systems and reports. If we improve timeliness and access to services we will increase the trust of citizens in government.

OpenData is also the result of several citizen consultations. During these sessions, citizens expressed a wish that government would:

- provide timely access to services and information

- make services findable and user-friendly

- put the focus on services and the ability to get help from a government representative if needed.

We were also advised by the public to redesign our website, acting on the following suggestions to:

- move from a communications site to a service site

- emphasise the photo banner, which shows scenery from the citizen's local area, to inspire pride in the province 
- move toward more life-event bundling (linking registries such as births, marriages, deaths and passport applications) and expansion of online services, and

- create a premier's page via which citizens can connect with their provincial government.

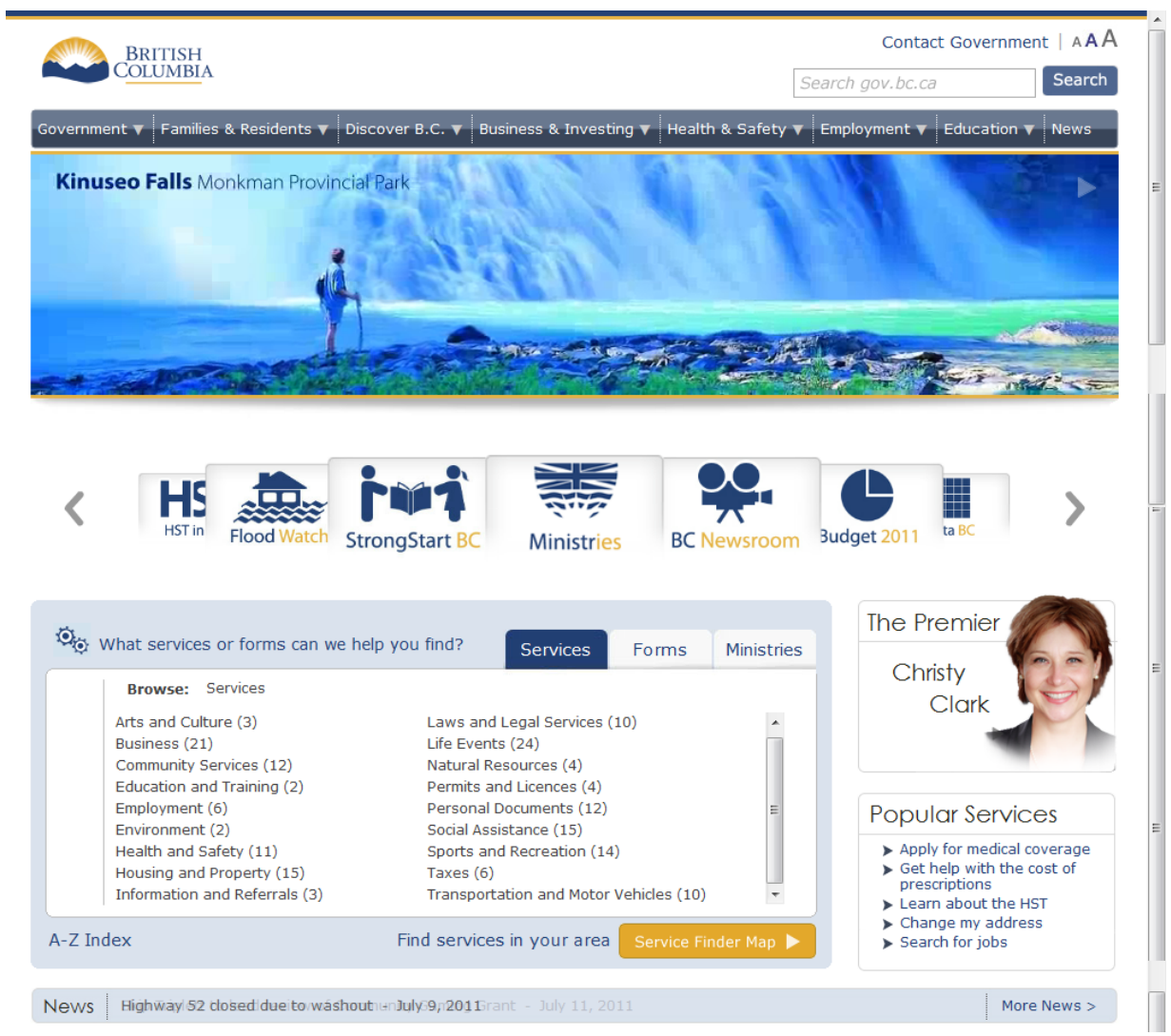

Figure 4: Official website for the province of British Colombia

Source: http://www2.gov.bc.ca/

We also encouraged collaboration with citizens for ideas to modernise the province's Water Act, a piece of legislation that is over 100 years old. The response was significant: nearly 27,000 visits to a purpose-built website and blog, as well as 500 people attending 12 face-to-face sessions across the province. Additionally, we received nearly 2000 submissions via blog, fax, email and mail over two phases of dialogue: one that sought input on what the Water Act could be, and one that put forward proposals for change to the existing legislation. The process is not yet complete; and a revised Act, with the focus on water sustainability, has yet to be legislated. 
To paraphrase the eighteenth century Scottish philosopher David Hume, the magic happens when you connect policy development to people's passion, and that close contact creates empathy between government and the public through shared experience and understanding.

To conclude, I will outline some of the systemic lessons we have learned at Service BC during the process of improving service delivery in British Colombia. Namely, that:

- visionary leadership is essential

- paying heed to citizens' expectations and experience is fundamental

- research must be action-based

- ongoing measurement is critical to facilitating adjustments and sustaining engagement

- success rests on developing, nurturing and sustaining a spirit of community, partnership and collaboration

- creating a central platform for horizontal collaboration such as the ICCS is extremely important

- we need to be brave, try a new business process, utilise new technology, experiment with new business models and learn to take risks.

And, finally, here are some words of advice for fellow public policy practitioners:

- clear all content for approval expeditiously and build trust between communications personnel and program personnel

- being agile is critical, but it takes a lot of work on process to limber up

- invest in specialised software for text analysis to automate the process of sifting, sorting and categorising comments

- engagement can be a powerful tool that is applicable in many other circumstances.

I hope you heed these lessons and advice in devising your own modes of engagement. 